\title{
Bilingualism: Language and Cognition \\ cambridge.org/bil \\ Cross-language activation in bimodal bilinguals: Do mouthings affect the co-activation of speech during sign recognition?
}

\section{Research Article}

Cite this article: Ormel E, Giezen MR, Van Hell JG (2022). Cross-language activation in bimodal bilinguals: Do mouthings affect the co-activation of speech during sign recognition? Bilingualism: Language and Cognition 25, 579-587. https://doi.org/10.1017/ S1366728921000845

Received: 20 December 2019

Revised: 4 August 2021

Accepted: 19 August 2021

First published online: 28 January 2022

Keywords:

cross-language activation; bimodal

bilingualism; mouthings; sign-picture verification

Address for correspondence: Ellen Ormel, Department of Linguistics, Centre for Language Studies, Radboud University Nijmegen, P.O. Box 9103, 6500 HD Nijmegen, The Netherlands. Ellen.Ormel@ru.nl.
Ellen Ormel ${ }^{1}$, Marcel R. Giezen ${ }^{2}$ and Janet G. Van Hell ${ }^{3}$ (D)

${ }^{1}$ Centre for Language Studies, Radboud University, Nijmegen, The Netherlands; ${ }^{2}$ BCBL. Basque Center on Cognition, Brain, and Language, San Sebastian, Spain and ${ }^{3}$ Department of Psychology and Center for Language Science, Pennsylvania State University, Stage College, United States

\begin{abstract}
The present study provides insight into cross-language activation in hearing bimodal bilinguals by (1) examining co-activation of spoken words during processing of signs by hearing bimodal bilingual users of Dutch (their L1) and Sign Language of the Netherlands (NGT; late learners) and (2) investigating the contribution of MOUTHINGs to bimodal cross-language activation. NGT signs were presented with or without mouthings in two sign-picture verification experiments. In both experiments the phonological relation (unrelated, cohort overlap or final rhyme overlap) between the Dutch translation equivalents of the NGT signs and pictures was manipulated. Across both experiments, the results showed slower responses for sign-picture pairs with final rhyme overlap relative to phonologically unrelated sign-picture pairs, indicating co-activation of the spoken language during sign processing, but no significant effect for sign-picture pairs with cohort overlap in Dutch. In addition, co-activation was not affected by the presence or absence of mouthings.
\end{abstract}

\section{Introduction}

Research has demonstrated that bilinguals of two spoken languages co-activate both languages when speaking, reading or listening in one language (for reviews, see e.g., Dijkstra \& van Heuven, 2002; Kroll, Bogulski \& McClain, 2012; Shook \& Marian, 2013; van Hell \& Tanner, 2012). In addition, several studies show robust effects of cross-language activation in deaf and hearing bilinguals of languages that do not share phonological form, i.e., signed and spoken languages, which is also the focus of the current study (for review, see Emmorey, Giezen \& Gollan, 2016; Ormel \& Giezen, 2014).

For example, Morford, Wilkinson, Villwock, Piñar and Kroll (2011) found that deaf American Sign Language (ASL)-English bilinguals were faster to decide that two English words were semantically related (e.g., bird and $d u c k$ ) when the ASL sign translation equivalents of these words overlapped in sign phonology (the signs BIRD and DUCK have the same location and movement and only differ in handshape). Conversely, they were slower to decide that two printed English words were not semantically related when their ASL translation equivalents overlapped in sign phonology. Ormel, Hermans, Knoors and Verhoeven (2012) obtained comparable findings in a word-picture verification study with bilingual deaf children learning Dutch and Sign Language of the Netherlands (NGT). Children responded slower and were less accurate when words and pictures were phonologically related in NGT than when they were unrelated. These findings have since been replicated in various other studies with deaf signers (e.g., Kubuş, Villwock, Morford \& Rathmann, 2015; Meade, Midgley, Sevcikova Sehyr, Holcomb \& Emmorey, 2017; Morford, Kroll, Piñar \& Wilkinson, 2014; Morford, Occhino-Kehoe, Piñar, Wilkinson \& Kroll, 2017), and in studies with native and non-native hearing signers (e.g., Giezen, Blumenfeld, Shook, Marian \& Emmorey, 2015; Giezen \& Emmorey, 2016; Shook \& Marian, 2012; Villameriel, Dias, Costello \& Carreiras, 2016; Williams \& Newman, 2015). Thus, cross-language activation is not only a robust characteristic of bilingual processing in bilinguals of spoken languages, but also in deaf and hearing signers, which we will refer to as 'bimodal bilinguals'.

For bilinguals of two spoken languages, one likely source of co-activation is through phonological overlap between words in different languages, as seen in, for example, cross-language phonological priming effects (e.g., Dijkstra \& van Heuven, 2002; van Hell \& Tanner, 2012). However, since spoken and sign languages have no shared phonological system, evidence for co-activation in bimodal bilinguals has been taken to suggest an important role for connections between lexical phonological and orthographical representations in the two languages 
and/or connections through shared semantic representations (Morford et al., 2017; Ormel, 2008; Shook \& Marian, 2012).

Alternatively, modality-specific connections between spoken and signed languages might account for language co-activation in bimodal bilinguals: for example, connections through signs that contain fingerspelled letters linked to their spoken translations (i.e., signs that contain "a direct representation of English orthographic features in (American) Sign Language sublexical form"; Morford, Occhino, Zirnstein, Kroll, Wilkinson \& Piñar, 2019 , p. 356). Fingerspelling is the manual encoding of written language, in which each letter of an alphabetic script is represented by a distinct hand configuration: that is, manual orthography. A growing number of studies have linked fingerspelling to reading acquisition and ability in deaf signers (Morere \& Allen, 2012; Stone et al., 2015). Fingerspelling can be used to sign unfamiliar words, and in many sign languages some conventionalized forms of fingerspelling have been integrated into the signed lexicon as loan words (lexicalized fingerspelling) or 'initialized signs'. Initialization is an effect of contact between signed and spoken languages that has resulted in a direct representation of orthographic features from the spoken language in manual signs: for example, by including a handshape that is associated with the first letter(s) of the orthographic translation equivalent (e.g., the sign for BLUE in NGT, which contains the letters ' $b$ ' and ' 1 ' from the Dutch translation equivalent 'blauw'). Morford et al. (2019) tested the impact of such direct representations of orthographic features in some ASL signs on language co-activation, and found that signs containing fingerspelled letters overlapping with the orthographic onset of their English translation equivalents did not affect cross-language activation in deaf signers.

Another feature that may drive language co-activation in bimodal bilinguals is mouthings that co-occur with signs and that also share phonological properties with spoken language. Mouthings refer to mouth actions during sign production that map onto phonological representations of the spoken language (i.e., they usually reflect one or more syllables of the spoken translation equivalent of the sign). According to Bank, Crasborn and van Hout's corpus study (2011, 2018), mouthings accompany $61 \%$ of the signs in Sign Language of the Netherlands (NGT). In contrast, MOUTH GESTURES are linguistically relevant mouth actions that do not map onto phonological representations of the spoken languages. While mouth gestures are often regarded as an integral part of the sign language lexicon (Boyes Braem, 2001), the status of mouthings in sign language processing is a topic of ongoing debate. According to some researchers, mouthings are also stored as part of the lexical representation of signs (e. g., Boyes Braem, 2001; Sutton-Spence \& Day, 2001). Others have argued, however, that mouthings do not form part of the sign language lexicon (e.g., Ebbinghaus \& Heßmann, 2001), and should be considered as a form of language mixing similar to the blending of spoken and signed utterances by hearing signing children and adults (e.g., Bank et al., 2016; Giustolisi, Mereghetti \& Cecchetto, 2017). This is supported by an experimental study showing that mouthings and signs are separately accessed in the mental lexicon (Vinson, Thompson, Skinner, Fox \& Vigliocco, 2010).

Especially for hearing bimodal bilinguals who have full access to the (visual) phonological system underlying mouthings, mouthings may boost language co-activation, but this possibility has not been tested yet. In order to directly assess the contribution of mouthings to co-activation patterns in bimodal bilinguals, the current study investigates the co-activation of spoken words during the processing of signs. To our knowledge, only two studies have examined co-activation of spoken phonological forms while bimodal bilinguals were processing signs (Hosemann, Mani, Herrmann, Steinbach \& Altvater-Mackensen, 2020; Lee, Meade, Midgley, Holcomb \& Emmorey, 2019). Lee et al. (2019) recorded electrophysiological responses (ERPs) in deaf and hearing ASL-English bilinguals who viewed sign pairs in ASL and were asked to judge their semantic relatedness. Part of the sign pairs rhymed in English and were also orthographically similar. The study showed no effects of language co-activation in the behavioral responses. However, the hearing signers showed a smaller N400 for sign pairs that were phonologically related in English. Interestingly, a reversed effect was found for deaf bilinguals, who showed a larger N400 for phonologically related pairs (although this effect was only observed in deaf participants who were unaware of the experimental manipulation). The deaf signers also showed a later and weaker N400 effect than the hearing signers. Lee et al. suggested that this might be due to the fact that English was the non-dominant language for the deaf signers. Hosemann et al. (2020) recorded ERPs from deaf native German Sign Language (DGS)-German bilinguals while viewing signed sentences containing prime and target signs that rhymed in German and were also orthographically similar. Their results demonstrated a smaller N400 for target signs for which the translation equivalents in spoken German were phonologically related to the translation equivalents of the primes, again suggesting that cross-language activation in deaf bimodal bilinguals also occurs in this direction. However, neither study considered the potential contribution of mouthings to the observed co-activation patterns.

To examine the impact of mouthing on cross-language activation patterns, the present study contrasted co-activation of spoken words during sign processing in HEARING bimodal bilinguals when signs were presented with mouthing (Experiment 1) or without mouthing (Experiment 2). To this end, we conducted two signpicture verification experiments with hearing Dutch adults who were late learners of NGT, in which we manipulated the phonological relation (unrelated vs. cohort overlap or final rhyme overlap) between the Dutch translation equivalents of the NGT signs and pictures.

The aim of the present study is twofold: 1) to provide insight into cross-language activation in hearing bimodal bilinguals by examining the co-activation of spoken words during processing of signs by hearing bimodal bilingual users of NGT (late learners) and Dutch (their L1), adding to recent findings in the literature of co-activation of signs during processing of written and spoken words, and 2) to elucidate the contribution of MOUTHINGs to the co-activation of spoken language during processing of sign language. Given that spoken and signed languages have no clear phonological connections (shared phonemes or graphemes) through which co-activation can occur, cross-language activation in bimodal bilinguals may occur through lexical connections between the two languages and/or through shared semantic representations (Morford et al., 2017; Ormel, 2008; Shook \& Marian, 2013). Alternatively, mouthings that share linguistic features with the spoken language might provide modality-specific connections between the spoken and signed languages that mediate language co-activation between these languages. Framed in the context of an adaptation of the Bilingual Interactive Activation+ (BIA+) model (Dijkstra \& van Heuven, 2002) for bimodal bilinguals (Morford et al., 2017; Ormel, 2008; Ormel et al., 2012), the current study will therefore test the following two hypotheses. 
If mouthings play a critical (bridging) role in cross-language activation between spoken language and sign language, i.e., if bimodal bilinguals link the mouthing patterns to the (visual) phonological representation of the spoken language, then co-activation of spoken language representations during sign recognition should be modulated by the presence or absence of mouthings (as depicted in Figure 1).

Alternatively, if spoken language is co-activated primarily through lexical-semantic links between signed and spoken languages, then co-activation should occur regardless of whether signs are accompanied by mouthings (as depicted in Figure 2).

\section{Experiment 1: Signs presented with mouthings}

\section{Method}

\section{Participants}

Twenty-four sign language interpreters in training ( 23 females, 1 male; Mean age $=22.6, S D=3.04$ ) participated in Experiment 1. All were in their final year of a four-year full-time sign language interpreter program at the Hogeschool Utrecht (HU University of Applied Sciences), The Netherlands. The native language of all participants was Dutch. They all started learning NGT during their sign language interpreter program, and thus were all late learners of NGT. Average self-rated language proficiency in NGT was $5.46(S D=.51)$ on a Likert scale ranging from 1 (nonfluent language usage) to 7 (comparable to native language usage), between the scores for 'good' (5) and 'very good' (6). None of the participants were familiar with another sign language, but all were to some extent fluent in English. The average self-rated proficiency for English was $4.67(S D=1.58)$.

\section{Materials}

120 videos of lexical signs and 120 black and white line drawings were used, in order to create 240 sign-picture pairs. The line drawings were selected from the picture database at the Max Planck Institute for Psycholinguistics and the picture database created by Snodgrass and Vanderwart (1980). The signs (10 x 5 $\mathrm{cm}$ ) and drawings $(5 \times 5 \mathrm{~cm})$ were simultaneously presented on the left and right side of a computer screen, respectively. The lexical signs were produced by a deaf native signer of NGT. Each sign was recorded twice within the same recording session, once with mouthing, thus mapping onto the (visual) phonological representations of spoken Dutch (used in Experiment 1) and once without mouthing (used in Experiment 2). The experimental items consisted of sign-picture pairs with either word-initial cohort overlap between the Dutch translation equivalents (e.g., the sign KERK [CHURCH]-picture of kers [cherry]), see Appendix A, or word-final rhyme overlap (e.g., the sign MUUR [WALL]-picture of [fire]), see Appendix B. For pairs with cohort overlap, the initial 2-4 letters and accompanying sounds of the Dutch equivalent were shared, always containing at least one consonant (word onset) and vowel (nucleus). For pairs with rhyme overlap, the final 2-4 letters and accompanying sounds of the Dutch equivalent were shared, always containing at least one vowel (nucleus) and consonant (coda) $)^{1}$.

\footnotetext{
${ }^{1}$ There is no one-to-one mapping of sounds and lip patterns. While we did not control the relation between sounds and lip patterns in the present study, we would like to note that the majority of non-overlapping items in the critical conditions (i.e., conditions 2 and 4) were created with a substantial phonological difference, including a vowel, which creates a clear visual difference in lip patterns.
}

Design

Eighty out of the 240 sign-picture pairs were divided across four critical experimental conditions, with 20 pairs in each of these four experimental conditions: cohort overlap-phonologically related (20 pairs), cohort unrelated (20 pairs), final rhyme overlap-phonologically related (20 pairs), final rhyme unrelated (20 pairs), see Table 1 . There were 240 sign-picture pairs in total ( 80 critical pairs and 160 fillers, see below), half in which the sign and the picture referred to the same concept, requiring a 'yes' response, and half in which the sign and picture did not match, requiring a 'no' response. All 80 critical sign-picture pairs required a 'no' response (i.e., sign and picture did not match). The signs and pictures in the two phonologically-related experimental conditions (cohort and rhyme overlap) were recombined to create sign-picture pairs for the phonologically-unrelated experimental conditions. That is, each sign in the critical conditions was paired with two pictures, one that was phonologically related (e.g., KERK-kers [CHURCH-cherry]) and one that was phonologically unrelated (e.g., KERK-haai [CHURCHshark]).

The remaining 160 sign-picture pairs were used as fillers (see Table 1). These filler trials consisted of 80 filler trials in which 40 different sign-picture combinations were repeated once, similar to the repetition of items in the experimental conditions, but all requiring a yes-response (i.e., sign and picture matched). The remaining 80 filler trials entailed 40 sign-picture combinations that were once presented as a matching pair (yes-response) and once recombined as a mismatching pair (no-response). This was done to prevent strategic behavior that the second occurrence of a sign or picture always implied the same response as for the first occurrence.

To avoid repetition effects, the same signs or pictures were always separated by a minimum of 50 different items. Across the entire experiment, 120 trials elicited a no-response (80 trials across 4 experimental conditions and 40 filler trials) and 120 trials elicited a yes-response (all filler trials). None of the sign-picture pairs in the experiment overlapped in NGT phonology (i.e., manual features, such as the location or the orientation of the hands and aspects related to handshapes and movements), and their Dutch translation equivalents were matched for word length, frequency, and number of orthographical neighbors across conditions, using the CELEX database (Baayen, Piepenbrock \& van Rijn, 1993).

\section{Procedure}

E-Prime version 2.0 (Psychology Software Tools, Inc) was used to present the stimuli. An E-prime response box measured participants' response latency. The left response button was marked with 'different' ('no' response) and the right response button with 'same' ('yes' response). Response latency was measured from the moment the signs and pictures appeared on the screen until participants pressed one of the buttons.

Participants were individually tested in a quiet room. They were seated $50 \mathrm{~cm}$ from the monitor and used their left and right index fingers to press the two response buttons. Participants were told to indicate whether a sign and a picture referred to the same concept or not by pressing the corresponding response button. The experiment consisted of six blocks of 40 trials preceded by three practice trials, with a short 30 -second break between blocks. Trial presentation within each block was randomized. The experiment took between 45 and 50 minutes. 


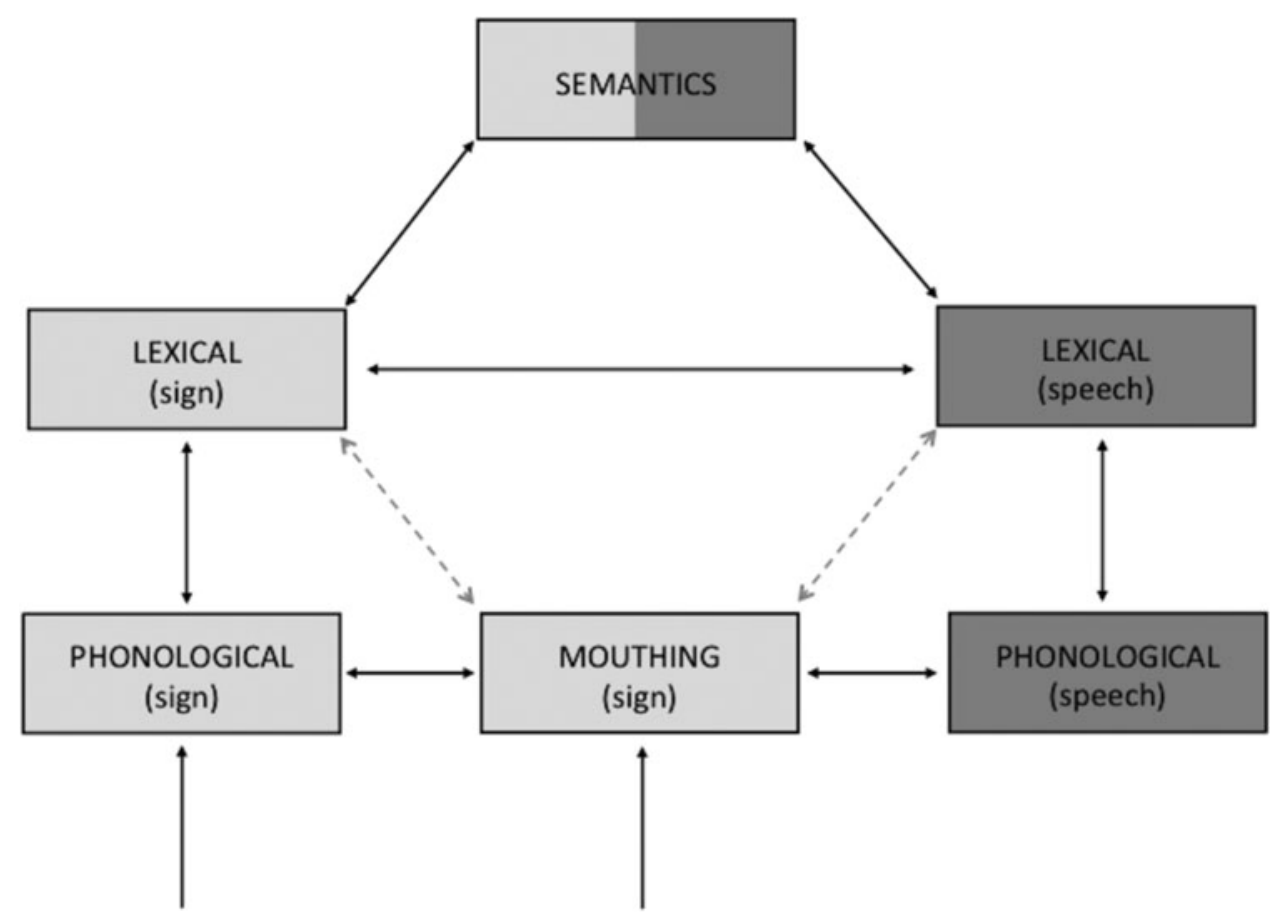

Fig. 1. Schematic representation of language co-activation for bimodal bilinguals based on the hypothesis that mouthings play a bridging role in modulating crosslanguage activation between spoken and signed languages. Dotted lines represent a potential direct connection between mouthings and lexical spoken/signed representations not tested in this study. Orthographic representations and connections are not shown in the Figure.

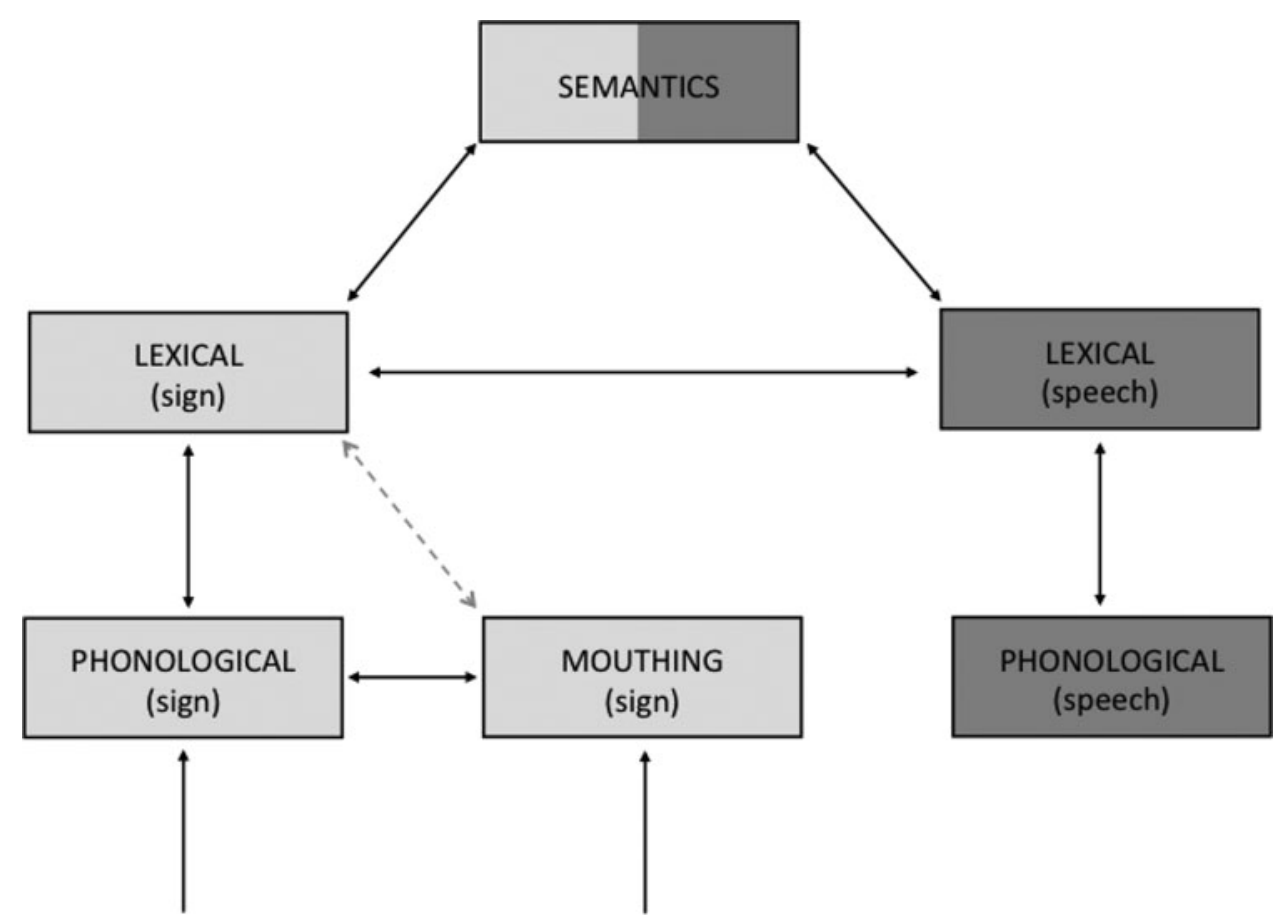

Fig. 2. Schematic representation of language co-activation for bimodal bilinguals based on the hypothesis that mouthings do not modulate cross-language activation between spoken and signed languages.

\section{Results}

Accuracy scores approached ceiling and were therefore not further analyzed (cohort condition: $M=99 \%(S D=.11)$ for phonologicallyrelated pairs and $M=99 \%(S D=.12)$ for phonologically-unrelated pairs; final rhyme condition: $M=100 \% \quad(S D=.05)$ for phonologically-related pairs and $M=99 \% \quad(S D=.08)$ for phonologically-unrelated pairs).

Analyses of the reaction time (RT) data were performed on the correct responses. Trials with RTs more than two standard 
Table 1. Experimental conditions.

\begin{tabular}{|c|c|c|c|}
\hline Type & Condition & $\mathrm{N}$ & Example SIGN - speech \\
\hline \multirow[t]{2}{*}{ Cohort } & Phonologically-related & 20 & $\begin{array}{l}\text { KERK - kers } \\
\text { [CHURCH - cherry] }\end{array}$ \\
\hline & Phonologically unrelated & 20 & $\begin{array}{l}\text { KERK - haai } \\
\text { [CHURCH - shark] }\end{array}$ \\
\hline \multirow[t]{2}{*}{ Final rhyme } & Phonologically-related & 20 & $\begin{array}{l}\text { MUUR - vuur } \\
\text { [WALL - fire] }\end{array}$ \\
\hline & Phonologically-unrelated & 20 & $\begin{array}{l}\text { MUUR - das } \\
\text { [WALL - scarf] }\end{array}$ \\
\hline \multirow[t]{2}{*}{ Fillers } & Yes-response & 120 & $\begin{array}{l}\text { TUIN - tuin } \\
\text { [GARDEN - garden] }\end{array}$ \\
\hline & No-response & 40 & $\begin{array}{l}\text { BOOM - dief } \\
\text { [TREE - thief] }\end{array}$ \\
\hline
\end{tabular}

deviation above or below the item mean RT or the participant mean RT were excluded from analysis. In total, $2 \%$ of the RT responses were excluded from the analysis. The data were analyzed with a GLM Repeated Measures ANOVA using IBM SPSS software as a within-subject $2 \times 2$ factorial design with reaction time of the correct responses as dependent variable. The two factors were Overlap (phonologically-related vs. phonologicallyunrelated in Dutch) and Position (cohort overlap vs. final rhyme overlap).

Mean RTs are presented in Figure 3. The main effect of Overlap was not significant, $F(1,23)=.59, p=.45, \eta_{\mathrm{p}}^{2}=.03$. The main effect of Position was significant, $F(1,23)=4.95, p<.05$, $\eta_{\mathrm{p}}^{2}=.18$, and the interaction between Overlap and Position was also significant, $F(1,23)=9.72, p<.01, \eta_{\mathrm{p}}^{2}=.30$. To further explore this interaction, we conducted follow-up simple effects analyses for the cohort overlap and final rhyme overlap condition separately. In the cohort condition, the effect of phonological overlap did not reach significance, $F(1,23)=2.42, \quad p=.13, \eta_{\mathrm{p}}^{2}=.10$, although Figure 3 suggests a trend towards FASTER responses for phonologically-related sign-picture pairs. In contrast, the effect of phonological overlap was significant in the final rhyme condition, $F(1,23)=8.07, p<.01, \eta_{\mathrm{p}}^{2}=.26$, indicating sLOWER responses for phonologically-related sign-picture pairs.

\section{Discussion}

The results from Experiment 1 show co-activation of spoken words during sign processing in hearing late learners of a sign language when signs were presented with mouthings. Specifically, participants were slower to decide that signs and pictures did not match when the Dutch translation equivalents overlapped in final rhyme. Interestingly, an asymmetric pattern was observed for items with word-initial (cohort) and word-final (rhyme) phonological overlap. While rhyme overlap yielded a significant interference effect, indicating cross-language activation, no significant effect of cohort overlap on response times was observed. We will postpone discussion of this difference between cohort and rhyme overlap until the General Discussion.

\section{Experiment 2: Signs presented without mouthings}

In Experiment 2, the same sign-picture pairings as in Experiment 1 were presented to a new group of hearing sign language interpreters, but now signs were presented WITHOUT their corresponding mouthings.

\section{Method}

\section{Participants}

A newly recruited group of 24 sign language interpreters in training (all females; Mean age $=26.9, S D=8.5$ ) participated in Experiment 2. They were recruited from the same population as tested in Experiment 1, and all participants were in their final year of a four-year full-time sign language interpreter program at the Hogeschool Utrecht (HU University of Applied Sciences), The Netherlands. The native language of all participants was Dutch and they were all late learners of NGT. Their average self-rated NGT proficiency was 5.26 $(S D=.69)$ and average self-rated English proficiency was 5.2 $(S D=.69)$. None of the participants were familiar with another sign language.

Materials. The same sign-picture pairs were used as in Experiment 1, but the videos of signs without mouthings were used in this experiment. In all other aspects, the experimental design and procedure were identical to Experiment 1.

\section{Results}

As in Experiment 1, accuracy scores were near ceiling and therefore not further analyzed (cohort condition: $M=98 \%(S D=.13)$ for phonologically-related pairs and $M=98 \%(S D=.13)$ for phonologically-unrelated pairs; final rhyme condition: $M=99 \%$ $(S D=.10)$ for phonologically-related pairs and $M=99 \%$ $(S D=.12)$ for phonologically-unrelated pairs).

Using the same outlier removal procedures as in Experiment 1, $1 \%$ of the RT responses were excluded from the analysis. As in Experiment 1, the data were analyzed as a within-subjects $2 \times 2$ factorial design with Overlap (phonologically-related vs. phonologically-unrelated in Dutch) and Position (cohort overlap vs. rhyme overlap) as factors.

Mean RTs are presented in Figure 4. Similar to Experiment 1, the main effect of Overlap was not significant, $F(1,23)=1.69$, $p=.21, \eta_{\mathrm{p}}^{2}=.07$, but there was a significant main effect of Position, $F(1,23)=10.37, \quad p<.01, \quad \eta_{\mathrm{p}}^{2}=.31$, indicating faster responses overall in the rhyme condition than cohort condition. In contrast to Experiment 1, however, the interaction between Overlap and Position was not significant in Experiment 2, $F(1,23)=1.19, p=.29, \eta_{\mathrm{p}}^{2}=.05$.

In order to compare the results of Experiment 2 with those of Experiment 1, we conducted simple effects analyses for the cohort overlap and rhyme overlap condition separately. In the cohort condition, there was no significant effect of phonological overlap, $F(1,23)<1$. In contrast, in the rhyme condition, the effect of phonological overlap was significant, $F(1,23)=5.58, \quad p=.03$ $\eta_{\mathrm{p}}^{2}=.02$, indicating slower responses for phonologically-related sign-picture pairs.

\section{Discussion}

Although neither the main effect of Overlap nor the interaction between Overlap and Position were statistically significant in Experiment 2, simple effects analyses showed a similar pattern as for Experiment 1: no effect of cohort overlap but significant interference for rhyme overlap. This result suggests that 


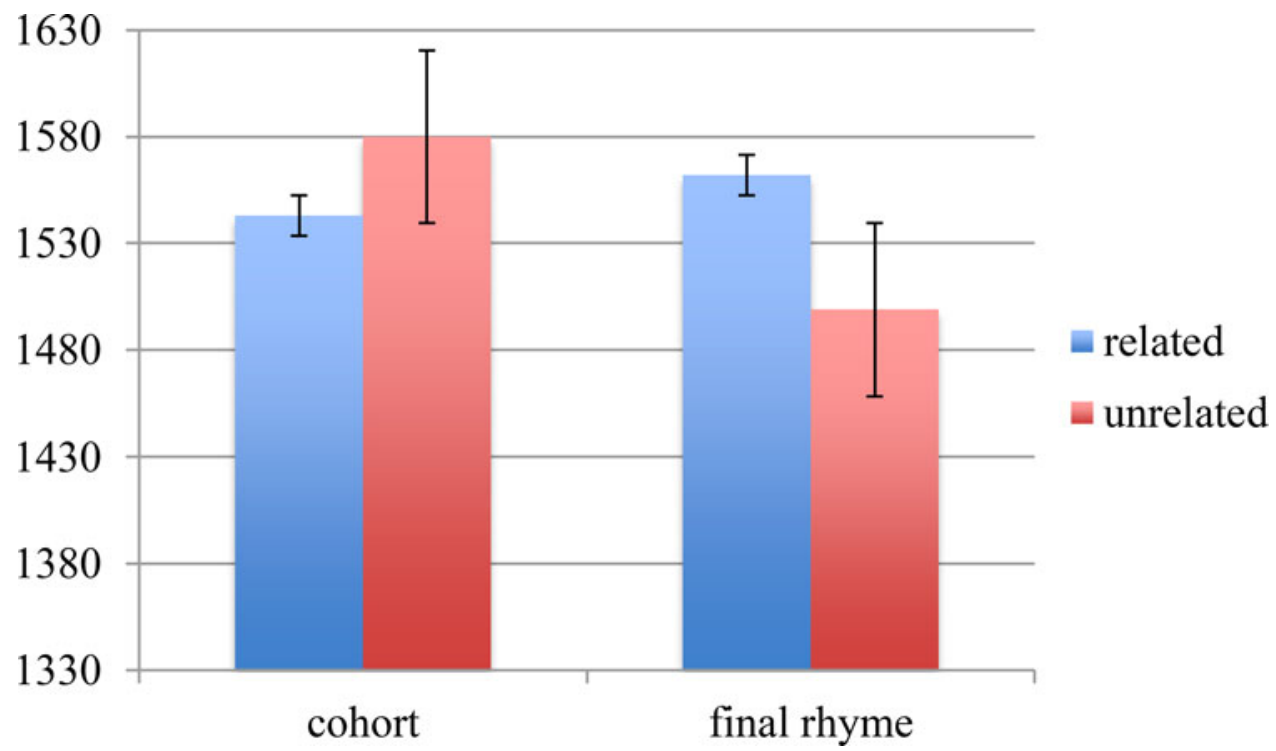

Fig. 3. Reaction times in Experiment 1 (wiтH mouthings) for cohort and final rhyme (error bars depict the standard error of the mean). The blue bars represent the results for the sign-picture pairs with overlapping (underlying) phonology in the L1 (spoken Dutch). The red bars reprent the results for the sign-picture pairs without any phonological overlap in the L1.

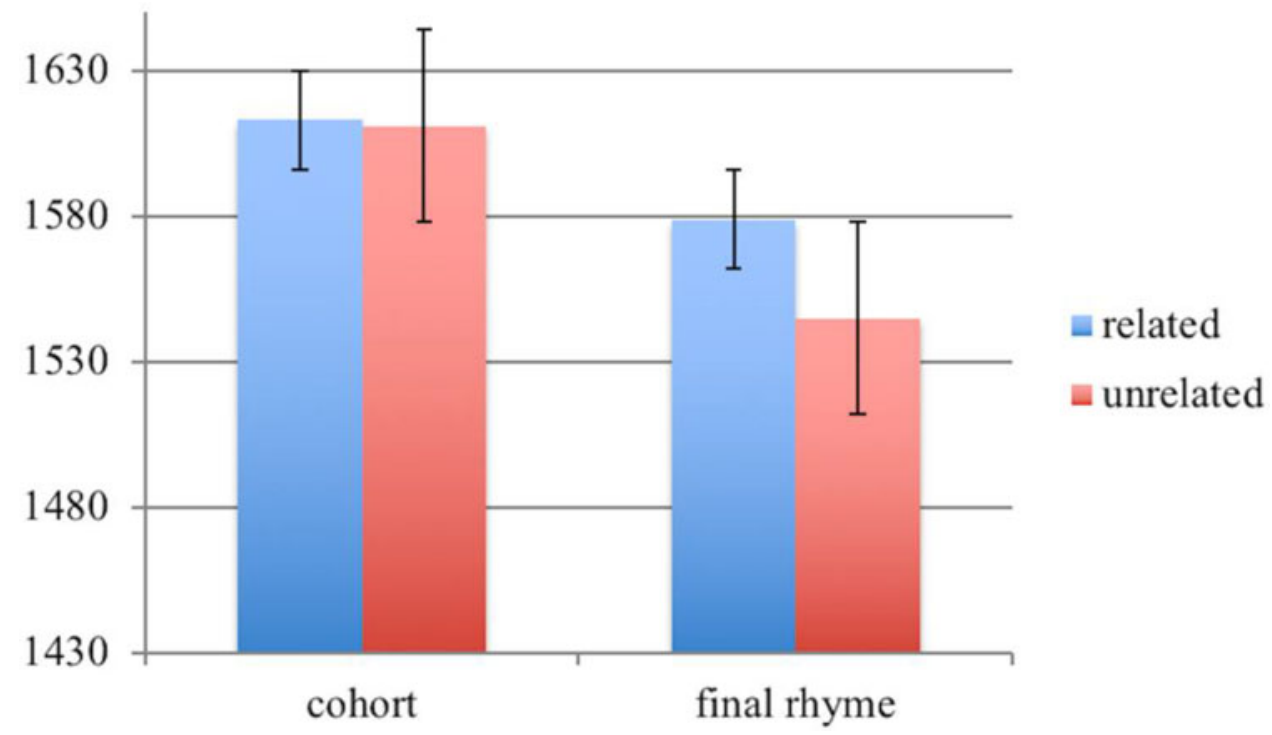

Fig. 4. Reaction times in Experiment 2 (wiтноит mouthings) for cohort and final rhyme rhyme (error bars depict the standard error of the mean). The blue bars represent the results for the sign-picture pairs with overlapping (underlying) phonology in the L1 (spoken Dutch). The red bars reprent the results for the signpicture pairs without any phonological overlap in the L1.

co-activation of the Dutch translation equivalents of NGT signs is unlikely driven by shared phonological patterns between mouthings and phonological representations of spoken words.

\section{Cross-experiment analysis}

To directly test whether the mouthing manipulation yielded different result patterns in Experiments 1 and 2, we conducted an overall analysis on the data from both experiments, treating Experiment as between-subjects factor. The main effect of Experiment was not significant, $F(1,46)<1$, nor were any of the interactions with Experiment (Position $\mathrm{x}$ Experiment: $F$ $(1,46)<1$, Overlap x Experiment: $F(1,46)<1$, Position $\mathrm{x}$
Overlap x Experiment: $F(1,46)=2.12, p=.15, \eta_{\mathrm{p}}^{2}=.04$. The main effect of Overlap was also not significant, $F(1,46)=2.22$, $p=.14, \eta_{\mathrm{p}}^{2}=.05$. In contrast, the main effect of Position was significant, $F(1,46)=14.97, p<.01, \eta_{\mathrm{p}}^{2}=.25$, as was the interaction between Overlap and Position, $F(1,46)=8.93, p<.01, \eta_{\mathrm{p}}^{2}=.16$, indicating slower responses for sign-picture pairs with final rhyme overlap in Dutch, but no significant effect of cohort overlap. This overall analysis confirms the outcome of the separate analyses for each experiment, and further supports the conclusion of co-activation for sign-picture pairs with final rhyme overlap in Dutch, but not for sign-picture pairs with cohort overlap. Importantly, this pattern holds for signs presented both with and without mouthings. 


\section{General discussion}

The aim of the present study was twofold: (1) to investigate the co-activation of L1 spoken words during the processing of signs in adult hearing late signers, and (2) to establish whether language co-activation is mediated by mouthings that are often co-produced with signed utterances in NGT and that map onto (visual) phonological representations of the spoken language. Hearing adult learners of NGT were tested in two sign-picture verification experiments in which a subset of the signs had Dutch translation equivalents that overlapped in phonology with the picture names at the beginning (cohort overlap) or end (rhyme overlap) of the word. The signs were either presented with mouthings (Experiment 1) or without mouthings (Experiment 2). In both experiments, we found slower responses for sign-picture pairs with final rhyme overlap in spoken Dutch (e.g., MUUR-vuur [WALL-fire]) relative to phonologically unrelated controls, but no significant effect for sign-picture pairs with cohort overlap in Dutch (e.g., KERK-kers [CHURCHcherry]).

Our findings extend previous studies with deaf and hearing signers that found co-activation of signs during the processing of written or spoken words (Giezen et al., 2015; Meade et al., 2017; Morford et al., 2011, 2014, 2017; Ormel, 2008; Ormel et al., 2012; Shook \& Marian, 2012; Villameriel et al., 2016) by showing that cross-language activation also occurs in the reverse direction, i.e., the co-activation of the spoken language during the processing of signs. The present results are consistent with the findings in two recent studies where ERP recordings revealed co-activation of words during sign processing (Hosemann et al., 2020; Lee et al., 2019), although these studies did not investigate the effect of mouthings. The combined findings strongly suggest that cross-language activation of spoken and signed languages by deaf signers and hearing bimodal bilinguals is bidirectional.

It should be noted that Lee et al. (2019) collected electrophysiological as well as behavioral data, but only found evidence for co-activation in the ERP responses. One possible explanation is that the different experimental paradigms used in these studies vary in their sensitivity to detect co-activation effects. For example, experiments with sign-picture stimuli as used in the present study may be more likely to elicit co-activation of words than experiments with only signed stimuli (see also Lee et al., 2019, for discussion).

The second aim of our study was to elucidate the contribution of MOUTHINGS to the co-activation of spoken language during processing of sign language. Because spoken and signed languages have no (direct) cross-language phonological connections (shared phonemes or graphemes), cross-language activation has been argued to occur through lexical connections between the two languages and/or through shared semantic representations (Morford et al., 2017; Ormel, 2008; Shook \& Marian, 2013). Alternatively, modality-specific connections between spoken and signed languages may account for language co-activation across the two language modalities: for example, signs with fingerspelled letters or signs with MOUTHINGS that share orthographic (i.e., fingerspelling) or (visual) phonological (i.e., mouthings) features with the spoken language (e.g., Emmorey et al., 2016; Kubuş et al., 2015). A recent study by Morford et al. (2019) found that cross-language activation was not affected by the presence of orthographic overlap between words and signs through initialization (signs containing fingerspelled letters overlapping with the onset of spoken translation equivalents).
The present study investigated the possibility that MOUTHINGS co-occurring with signs mediate cross-language activation of spoken words during sign processing (the second variant of the alternative explanation outlined above). We addressed this issue by presenting signs in a sign-picture verification task with mouthings in Experiment 1 and without mouthings in Experiment 2. The results indicate that mouthings, similar to initialization, do not affect the co-activation of representations in the non-target spoken language during sign processing for hearing late signers. This finding is in line with the model presented in Figure 2, in which connections between signs and spoken language representations at the lexical and/or semantic level allow for crosslanguage activation (cf. Morford et al., 2017; Ormel, 2008; Shook \& Marian, 2012).

Although the presence of mouthings did not affect the co-activation of words in the advanced late learners with high fluency levels tested in the present study, it remains to be seen whether this finding generalizes to beginning sign language learners or native signers, and to what extent language co-activation is impacted by relative proficiency in the sign language and spoken language. While previous studies have shown co-activation in both native and non-native signers, and deaf as well as hearing signers, detailed investigations of the impact of fluency on language co-activation in either direction in signers have not been carried out yet. As discussed in Chen, Bobb, Hoshino and Marian (2017), language co-activation in bilinguals is sensitive to fine-grained differences in the bilingual language experience, such as degree of language exposure to - and language fluency in - each of the languages. Furthermore, as suggested by Bank, Crasborn, and van Hout (2015), mouthings in isolated signs, such as in the present study, may not behave the same way as mouthings in discourse.

Another finding in both experiments in the present study is that cross-language activation was found for sign-picture pairs with final rhyme overlap only, and not for sign-picture pairs with cohort overlap. A possible explanation is that cohort and rhyme effects reflect differential contributions of pre-lexical and lexical influences in cross-language activation. Specifically, rhyme effects might reflect lexical co-activation of competitors, while cohort effects might primarily reflect bottom-up phonological co-activation of competitors (cf. Desroches, Newman \& Joanisse, 2009, on (pre-)lexical competition effects in monolingual word recognition). Most cross-language activation studies with unimodal bilinguals investigated cohort competition effects, and therefore may have primarily measured phonological competition between the two languages. If cross-language activation in bimodal bilinguals relies on connections at the lexical and/or semantic level between the two languages, then this could explain why only rhyme competitors, but not cohort competitors, yielded co-activation effects in the present study. Furthermore, it is consistent with the finding that mouthings, which also reflect a (visual) phonological connection between spoken and signed languages, did not modulate co-activation effects in the present study.

In addition to contributing to our understanding of bimodal bilingual language processing, the current findings add to general theories of bilingual language processing. In particular, the findings provide further empirical evidence for the answer to the question whether phonological overlap between languages is required for language co-activation (NO), whether co-activation in bimodal bilinguals extends to co-activation of spoken phonology during sign processing (YES), and if modality-specific 
language features that convey a potential link to the phonologically non-overlapping other language (here tested by mouthing, referring to the visual phonological form of a spoken language accompanying a sign) provide a bridging function for crosslanguage activation (NO).

In conclusion, the present study extends previous studies of co-activation of signs during spoken word processing in deaf and hearing bimodal bilinguals by demonstrating that hearing late signers also co-activate spoken words during sign processing, thereby indicating that the co-activation of signs and spoken words is bidirectional. Furthermore, this form of co-activation is not mediated by mouthings, providing further evidence for activation of lexical representations in the non-target language in the absence of phonological overlap between languages in the input. The impact of the degree of language fluency in the respective languages and the effect of linguistic experiences as a deaf or a hearing signer requires further investigation in order to fully grasp the mechanisms driving bimodal bilingual language comprehension.

Competing interests. The authors declare none

Acknowledgements. The authors thank Merel van Zuilen for her help in developing the stimuli, Daan Hermans for his valuable contribution to many aspects of the study, and Joyce van der Loop, Elselieke Hermes, Maaike Korpershoek, Maud Graste, and Marli van Sark for their valuable contributions to parts of the study.

\section{References}

Baayen RH, Piepenbrock R and van Rijn H (1993) The CELEX lexical database. Philadelphia, PA: University of Pennsylvania Linguistics Data Consortium.

Bank R, Crasborn O and van Hout R (2011) Variation in mouth actions with manual signs in Sign Language of the Netherlands (NGT). Sign Language \& Linguistics 14, 248-70. https://doi.org/10.1075/sll.14.2.02ban

Bank R, Crasborn O and van Hout R (2015) Alignment of two languages: The spreading of mouthings in Sign Language of the Netherlands. International Journal of Bilingualism 19(1), 40-55. https://doi.org/10. 1177/1367006913484991.

Bank R, Crasborn O and van Hout RWNM (2016). The prominence of spoken language elements in a sign language. Linguistics 54(6), 1-25.

Bank R, Crasborn O and van Hout R (2018) Bimodal code-mixing: Dutch spoken language elements in NGT discourse. Bilingualism: Language and Cognition 21(1), 104-120. http://doi.org/10.1017/S1366728916000936.

Boyes Braem P (2001) Functions of the mouthings in the signing of deaf early and late learners of Swiss German Sign Language (DSGS). In Boyes Braem P and Sutton-Spence R (eds), The hands are the head of the mouth: The mouth as articulator in sign languages. Hamburg: Signum Press, PP. 99-132.

Chen P, Bobb S, Hoshino N and Marian V (2017) Neural signatures of language co-activation and inhibitory control during bilingual spoken language comprehension. Brain Research 1665, 50-64.

Desroches AS, Newman RL and Joanisse MF (2009) Investigating the time course of spoken word recognition: electrophysiological evidence for the influences of phonological similarity. Journal of Cognitive Neuroscience 21 (10), 1893-1906. http://doi.org/10.1162/jocn.2008.21142.

Dijkstra T and van Heuven WJB (2002) The architecture of the bilingual word recognition system: From identification to decision. Bilingualism: Language and Cognition 5(3), 175-197. http://doi.org/10.1017/S1366728902003012.

Ebbinghaus $\mathbf{H}$ and Heßmann $\mathbf{J}$ (2001) Sign language as multidimensional communication: Why manual signs, mouthings, and mouth gestures are three different things. In Boyes Braem P and Sutton-Spence R (eds), The hands are the head of the mouth: The mouth as articulator in sign languages. Hamburg: Signum Press, PP. 133-151.

Emmorey K, Giezen MR and Gollan TH (2016) Psycholinguistic, cognitive, and neural implications of bimodal bilingualism. Bilingualism: Language and Cognition 19(2), 223-242. http://doi.org/10.1017/S1366728915000085.
Giezen M, Blumenfeld HK, Shook A, Marian V and Emmorey K (2015) Parallel language activation and inhibitory control in bimodal bilinguals. Cognition 141, 9-25. http://doi.org/10.1016/j.cognition.2015.04.009.

Giezen MR and Emmorey K (2016) Language co-activation and lexical selection in bimodal bilinguals: Evidence from picture-word interference. Bilingualism: Language and Cognition 19(2), 264-276. http://doi.org/10. 1017/S1366728915000097.

Giustolisi B, Mereghetti E and Cecchetto C (2017) Phonological blending or code mixing? Why mouthing is not a core component of sign language grammar. Natural Language \& Linguistic Theory 35, 347-365. https://doi. org/10.1007/s11049-016-9353-9.

Hosemann J, Mani N, Herrmann A, Steinbach M and Altvater-Mackensen N (2020) Signs activate their written word translation in deaf adults: An ERP study on cross-modal co-activation in German Sign Language, Glossa: A Journal of General Linguistics 5(1), 57. DOI: http://doi.org/10. 5334/gjgl.1014.

Kroll JF, Bogulski CA and McClain R (2012) Psycholinguistic perspectives on second language learning and bilingualism: The course and consequence of cross-language competition. Linguistic Approaches to Bilingualism 2(1), 1-24. http://doi.org/10.1075/lab.2.1.01kro.

Kubuş O, Villwock A, Morford JP and Rathmann C (2015) Word recognition in deaf readers: Cross-language activation of German Sign Language and German. Applied Psycholinguistics 36, 831-854. http://doi.org/10. 1017/S0142716413000520.

Lee B, Meade G, Midgley KJ, Holcomb PJ and Emmorey K (2019) ERP evidence of the co-activation of English words during the recognition of American Sign Language signs. Brain Sciences 9, 148. http://doi:10.3390/ brainsci9060148.

Meade G, Midgley KJ, Sevcikova Sehyr Z, Holcomb PJ and Emmorey K (2017) Implicit co-activation of American Sign Language in deaf readers: An ERP study. Brain and Language 170, 50-61. http://doi.org/10.1016/j. bandl.2017.03.004.

Morere D and Allen T (2012). Assessing literacy in deaf individuals. Neurocognitive measurement and predictors. New York NY: Springer.

Morford JP, Kroll JF, Piñar P and Wilkinson E (2014) Bilingual word recognition in deaf and hearing signers: Effects of proficiency and language dominance on cross-language activation. Second Language Research 30(2), 251-271. http://doi.org/10.1177/0267658313503467.

Morford JP, Occhino-Kehoe C, Piñar P, Wilkinson E and Kroll JF (2017) The time course of cross-language activation in deaf ASL-English bilinguals. Bilingualism: Language and Cognition 20(2), 337-350. http://doi.org/10. 1017/S136672891500067X.

Morford J, Occhino C, Zirnstein M, Kroll J, Wilkinson E and Piñar P (2019) What is the source of bilingual cross-language activation in deaf bilinguals? Journal of Deaf Studies and Deaf Education 24(4), 356-365. https://doi.org/10.1093/deafed/enz024.

Morford JP, Wilkinson E, Villwock A, Piñar P and Kroll JF (2011) When deaf signers read English: Do written words activate their sign translations? Cognition 118(2), 286-292. http://doi.org/10.1016/j.cognition.2010. 11.006 .

Ormel E (2008) Visual word recognition in bilingual deaf children. Dissertation, Radboud University, Nijmegen, The Netherlands.

Ormel E and Giezen MR (2014) Bimodal bilingual cross-language interaction: Pieces of the puzzle. In Marschark M, Tang G and Knoors H (eds), Bilingualism and bilingual deaf education. Oxford, NY: Oxford University Press, pp. 74-101.

Ormel E, Hermans D, Knoors H and Verhoeven L (2012) Cross-language effects in written word recognition: The case of bilingual deaf children. Bilingualism: Language and Cognition 15(2), 288-303. http://doi.org/10. 1017/S1366728911000319.

Shook A and Marian V (2012) Bimodal bilinguals co-activate both languages during spoken comprehension. Cognition 124(3), 314-324. http://doi.org/ 10.1016/j.cognition.2012.05.014.

Shook A and Marian V (2013) The Bilingual Language Interaction Network for Comprehension of Speech. Bilingualism: Language and Cognition 16(2), 304-324. http://doi.org/10.1017/S1366728912000466.

Snodgrass JG and Vanderwart M (1980) A standardized set of 260 pictures: Norms for name agreement, image agreement, familiarity and visual 
complexity. Journal of Experimental Psychology: Human Learning and Memory 6(2), 174-215.

Stone A, Kartheiser G, Hauser P, Petitto LA and Allen T (2015) Fingerspelling as a novel gateway into reading fluency in deaf bilinguals, PLOS ONE, 10(10), 1-12.

Sutton-Spence R and Day L (2001) Mouthings and mouth gestures in British Sign Language (BSL). In Boyes Braem P and Sutton-Spence R (eds), The hands are the head of the mouth: The mouth as articulator in sign languages. Hamburg: Signum Press, PP. 69-86.

van Hell JG and Tanner D (2012) Second language proficiency and crosslanguage lexical activation. Language Learning 62(S2), 148-171. http://doi. org/10.1111/j.1467-9922.2012.00710.x.
Villameriel S, Dias P, Costello B and Carreiras M (2016) Cross-language and cross-modal activation in hearing bimodal bilinguals. Journal of Memory and Language 87, 59-70. http://doi.org/10.1016/j.jml.2015. 11.005.

Vinson DP, Thompson RL, Skinner R, Fox N and Vigliocco G (2010) The hands and mouth do not always slip together in British Sign Language: Dissociating articulatory channels in the lexicon. Psychological Science 21 (8), 1158-1167. http://doi.org/10.1177/0956797610377340.

Williams JT and Newman SD (2015) Interlanguage dynamics and lexical networks in nonnative L2 signers of ASL: Cross-modal rhyme priming. Bilingualism: Language and Cognition 19(3), 453-470. http://doi.org/10. 1017/S136672891500019X.

\section{Appendices}

\section{Appendix A. Stimuli list cohort overlap}

\begin{tabular}{|lll|}
\hline Sign & $\begin{array}{l}\text { Phonologically related } \\
\text { picture }\end{array}$ & $\begin{array}{l}\text { Phonologically } \\
\text { unrelated picture }\end{array}$ \\
\hline boek (book) & boer (farmer) & duim (thumb) \\
\hline bos (forest) & bom (bomb) & koffer (suitcase) \\
\hline broer (brother) & broek (trousers) & hart (heart) \\
\hline duif (pidgeon) & duim (thumb) & boer (farmer) \\
\hline haak (hook) & haar (hair) & koe (cow) \\
\hline haan (rooster) & haai (shark) & kers (cherry) \\
\hline hark (rake) & hart (heart) & broek (trousers) \\
\hline hek (fence) & heks (witch) & lam (lamb) \\
\hline hert (deer) & hengel (rod) & trap (staircase) \\
\hline kast (cabinet) & kar (cart) & schaar (scissors) \\
\hline kerk (church) & kers (cherry) & haai (shark) \\
\hline koek (cake) & koe (cow) & haar (hair) \\
\hline koffie (coffee) & koffer (suitcase) & bom (bomb) \\
\hline lamp (lamp) & lam (lamb) & heks (witch) \\
\hline mug (mosquito) & muts (hat) & pen (pen) \\
\hline pet (cap) & pen (pen) & muts (hat) \\
\hline schaap (sheep) & schaar (scissors) & kar (cart) \\
\hline ster (star) & step (scooter) & tak (branch) \\
\hline tas (bag) & tak (branch) & step (scooter) \\
\hline tractor (tractor) & trap (staircase) & hengel (rod) \\
\hline
\end{tabular}

\section{Appendix B. Stimuli list final rhyme overlap}

\begin{tabular}{|lll|}
\hline Sign & $\begin{array}{l}\text { Phonologically related } \\
\text { picture }\end{array}$ & $\begin{array}{l}\text { Phonologically unrelated } \\
\text { picture }\end{array}$ \\
\hline beer (bear) & veer (feather) & maan (moon) \\
\hline bloed (blood) & hoed (hat) & krant (newspaper) \\
\hline boot (boat) & brood (bread) & rugzak (backpack) \\
\hline bril (glasses) & krokodil (crocodile) & meloen (melon) \\
\hline jas (coat) & das (scarf) & vuur (fire) \\
\hline kaas (cheese) & vaas (vase) & sneeuw (snow) \\
\hline kraan (tap) & maan (moon) & veer (feather) \\
\hline leeuw (lion) & sneeuw (snow) & vaas (vase) \\
\hline mes (knife) & fles (bottle) & mand (basket) \\
\hline muur (wall) & vuur (fire) & das (scarf) \\
\hline pijl (arrow) & bijl (axe) & mier (ant) \\
\hline plant (plant) & krant (newspaper) & hoed (hat) \\
\hline rivier (river) & mier (ant) & bijl (axe) \\
\hline rug (back) & brug (bridge) & kroon (crown) \\
\hline schoen (shoe) & meloen (melon) & krokodil (crocodile) \\
\hline slak (snail) & rugzak (backpack) & brood (bread) \\
\hline strand (beach) & mand (basket) & fles (bottle) \\
\hline trein (train) & konijn (rabbit) & ui (onion) \\
\hline trui (jumper) & ui (onion) & konijn (rabbit) \\
\hline zoon (son) & kroon (crown) & brug (bridge) \\
\hline
\end{tabular}

